\title{
Study on Rheological and Mechanical Properties of Aeolian Sand-Fly Ash-Based Filling Slurry
}

\author{
Xiaoping Shao ${ }^{1,2, *}$, Long Wang ${ }^{1}$, Xin Li ${ }^{1}$, Zhiyu Fang ${ }^{1, *}$, Bingchao Zhao ${ }^{1,2}$, Yeqing Tao ${ }^{1}$, \\ Lang Liu ${ }^{1,2}$, Wuliang Sun ${ }^{1}$ and Jianpeng Sun ${ }^{1}$ \\ 1 Energy School, Xi'an University of Science and Technology, Xi'an 710054, China; \\ 18203078025@stu.xust.edu.cn (L.W.); 18203078022@stu.xust.edu.cn (X.L.); zhaobc@xust.edu.cn (B.Z.); \\ 17203078021@stu.xust.edu.cn (Y.T.); liulang@xust.edu.cn (L.L.); 19203213045@stu.xust.edu.cn (W.S.); \\ 19203077025@stu.xust.edu.cn (J.S.) \\ 2 Key Laboratory of Western Mines and Hazards Prevention, Ministry of Education of China, \\ Xi'an 710054, China \\ * Correspondence: shaoxp@xust.edu.cn (X.S.); 17203078034@stu.xust.edu.cn (Z.F.)
}

Received: 9 February 2020; Accepted: 5 March 2020; Published: 9 March 2020

\begin{abstract}
Backfill mining is the most environmentally friendly mining method at present, which can effectively control the surface subsidence, improve the recovery rate, and has good social and economic benefits. The purpose of this study is to solve the environmental problems caused by solid waste, combined with the rich geographical advantages of aeolian sand in the Yushenfu mining area of China. The rheological properties of the aeolian sand-fly ash-based filling slurry with different fly ash content are studied by experiments, and the strength development law of the filling body under different age and fly ash content are studied from the macroscopic and microscopic points of view. The rheological experiments showed that the increase of the amount of fly ash has a significant effect on the thixotropy, plastic viscosity, and yield stress of the filling slurry. Additionally, rheological properties of aeolian sand-fly ash-based filling slurry conform to the Bingham model. With the increase of the amount of fly ash, the performance of the filling slurry has been significantly improved. Uniaxial test and scanning electron microscope observation showed that the influence of fly ash on the strength of the filling body was mainly reflected in the late stage of maintenance, but was not obvious in the middle stage. Fly ash particles mainly bear the role of "water reduction" and a physical filling effect, which makes the filling slurry thicker and the internal structure more closely spaced. The volcanic ash reaction of fly ash is lagging behind the hydration reaction of cement; the secondary product of the delayed reaction is filled in the pores of cement hydrates, which can greatly reduce the porosity of the backfill body and increase the later strength of the backfill body. It provides a guarantee for the safe replacement of coal pillars in the working face.
\end{abstract}

Keywords: coal mining backfill; fly ash content; uniaxial compression; aeolian sand

\section{Introduction}

For a long time, coal has played a pivotal role in China's energy economy. In the process of underground mining, traditional mining methods have caused a series of environmental problems such as surface subsidence, soil erosion, and desertification of the surface soil mass, which need to be resolved. In the northern Shaanxi Province Yushenfu mining area of China, the old room-pillar mining and the "narrow strip" coal mining methods have been used for a long time [1]. Although the purpose of controlling surface subsidence and water retention has been achieved within a period of time, the recovery rate can only reach about $50 \%$, which has caused serious waste of resources, and roof disasters have occurred frequently in recent years [2]. Strip mining areas also have hidden 
dangers of overburden disasters due to long-term creep of coal pillars [3]. Backfill mining, as a trend in modern mining, can effectively alleviate the above problems [4-7]. We have proposed a strip backfill mining method of "mining $7 \mathrm{~m}$ to retain $8 \mathrm{~m}$ " for a Shanghe coal mine, that is mining a $7 \mathrm{~m}$ wide strip and leaving an $8 \mathrm{~m}$ wide strip pillar [1]. It was found that after the filling slurry was pumped from the ground filling station to the goaf for solidification, the filling strength needed to be more than $6.0 \mathrm{MPa}$ to ensure the stability of the overburden in the process of coal pillar replacement [1]. The filling system is shown in Figure 1.

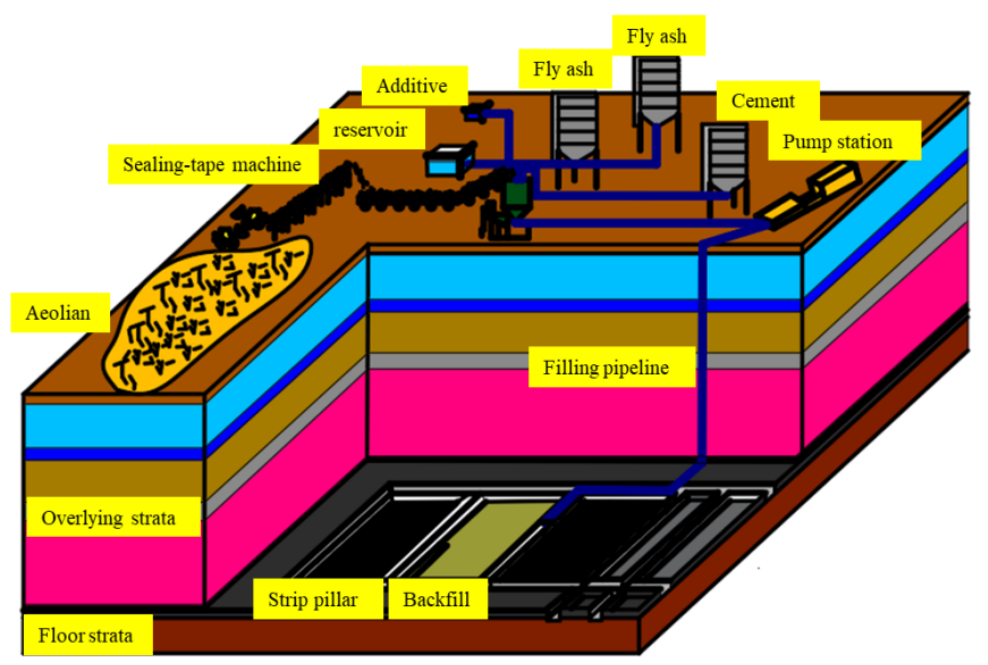

Figure 1. Strip filling diagram.

The selection and proportion of filling materials are very important to rheological and mechanical properties. However, conventional filling materials mostly use cement as a gelling agent, and cement accounts for about $70 \%$ of the total filling cost [8]. Meanwhile the filling materials (gangue, tailing) commonly used in Western China are not abundant [9], resulting in higher filling material costs. Most of the surface of the Yushenfu mining area is typically aeolian dunes, where there is abundant aeolian sand. Moreover, fly ash in the power plants around the mining area requires large-scale accumulation sites, and has caused serious environmental pollution [10,11]. Therefore, using aeolian sand and fly ash as the filling materials can not only reduce the amount of waste disposal and disposal costs, but also save cement and reduce the filling cost [12]. Engineering practice has proven that adding fly ash to structural concrete can improve concrete performance, increase concrete strength in the later period, increase the compactness and resistance to concrete, reduce the shrinkage of concrete [13-17], and bring good economic and social benefits [18-20]. Therefore, aeolian sand and fly ash are some of the more cost-effective paste filling materials in the Yushenfu mining area, China.

During the filling and mining process, the rheological performance of the filling slurry is a key consideration for the selection of filling pump stations and pipelines. Previous experiments have shown that fly ash can improve the flow properties of the slurry in pipelines and the suspension performance of solids [21,22]. Some scholars [23,24] studied the influence of different fly ash content on the rheological properties of waste rock filling slurry and gangue filling slurry by slump test and rheological test; furthermore, the influence of the type, content, and fineness of fly ash on the rheological behavior of cement and concrete has been reported by many scholars [25]. After the filling slurry is injected into the goaf, its solidification strength is a direct factor to measure the filling effect, and sufficient bearing strength will directly affect the stability of the overburden and the safety of the working face [26]. Dong et al. [27] established the evolution equation between the tensile strength and compressive strength of aeolian sand concrete, and studied the influence of the content of aeolian sand and fly ash on the mechanical properties of concrete. Cao et al. [28] showed that aeolian sand and mass concentration have the least influence on the compressive strength. When the content of aeolian 
sand exceeds $45 \%$, the compressive strength of the filling body gradually decreases. Agrawal et al. [29] found that fly ash concrete has higher mechanical strength and durability through the experiment of replacing river sand concrete with fly ash. Although in the past there was less research study on the performance of aeolian sand-fly ash-based filling materials, there is still significant further research.

In China, the Yushenfu mining area is different from other mining areas; this area is rich in aeolian sand materials. In order to solve the mining subsidence problem of the Yushenfu mining area, this article proposes a new type of mixture material, aeolian sand-fly ash-based filling material. Aeolian sand is used as the filling aggregate in this paper; the influence of fly ash contents on rheological properties and mechanical properties of aeolian sand fly ash based filling slurry is emphatically studied. The study results obtained the ratio of filling materials favorable for the Yushenfu mining area. This study not only improves the recovery rate safely, and effectively controls the surface subsidence, but also makes full use of the waste material (fly ash) and local abundant aeolian sand, greatly reducing the filling cost and environmental pollution, which has good social and economic benefits. It will provide reference to safe filling mining in the Yushenfu mining area and similar mines in the world.

\section{Experimental Materials and Methods}

\subsection{Experimental Materials}

In this experiment, we choose aeolian sand and fly ash as filling materials. Particle morphology and mineral composition of aeolian sand and fly ash were analyzed by laser particle size scanner and $\mathrm{X}$-ray fluorescence (XRF). The following is a detailed description of the two filling materials:

Aeolian sand: It is taken from the vicinity of Yulin area, China. Its main light minerals are quartz, feldspar and calcite, accounting for more than $90 \%$ of its minerals. The analysis of its mineral

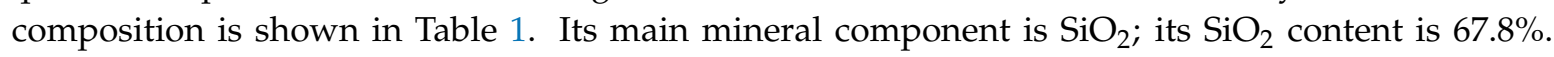
As shown in Figure $2 \mathrm{a}, \mathrm{d}_{50}$ and $\mathrm{d}_{90}$ are 214.8 and $357.3 \mu \mathrm{m}$, respectively, and the average particle diameter is $210.6 \mu \mathrm{m}$. The sieving test showed that the particle size distribution of aeolian sand was relatively uniform, and the sortability was good. The aeolian sand has very few sticky particles and powder particles.

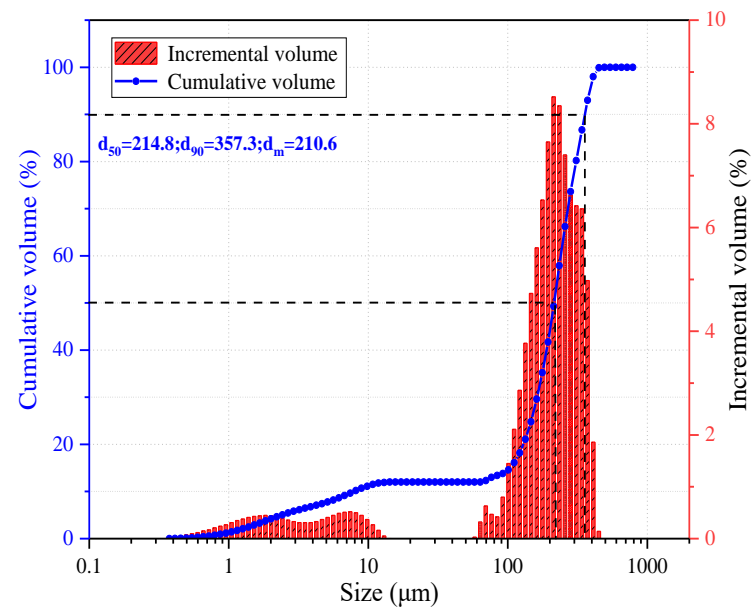

(a) Aeolian sand

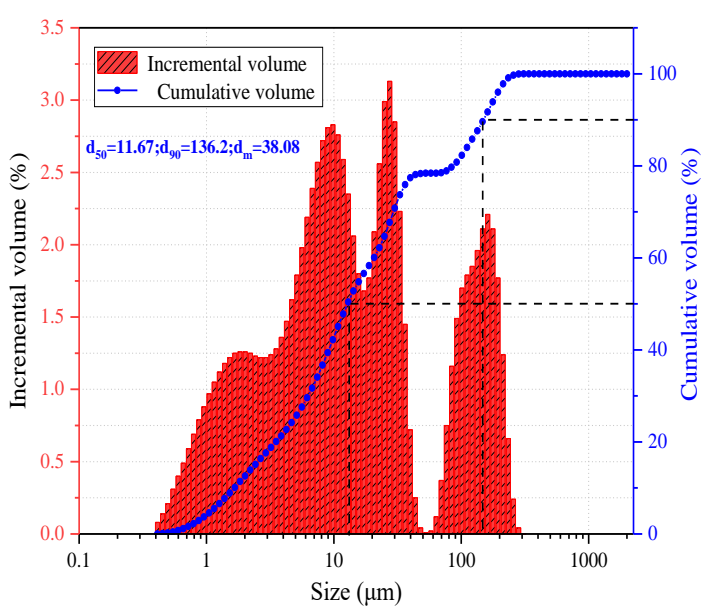

(b) Fly ash

Figure 2. Distribution curves of the particle size of aeolian sand and fly ash.

Table 1. Aeolian sand composition.

\begin{tabular}{lcccccc}
\hline Composition & $\mathrm{AL}_{2} \mathrm{O}_{3}$ & $\mathrm{SiO}_{2}$ & $\mathrm{~K}_{\mathbf{2}} \mathbf{O}$ & $\mathrm{CaO}$ & $\mathrm{Fe}_{2} \mathbf{O}_{3}$ & Others \\
\hline Content (\%) & 10.3 & 67.8 & 7.5 & 5.3 & 5.8 & 3.3 \\
\hline
\end{tabular}


Fly ash: It was taken from Hanglaiwan power plant of China and belongs to class II fly ash. The loss on ignition is $4.34 \%$. As shown in Figure $2 \mathrm{~b}, \mathrm{~d}_{50}$ is $11.67 \mu \mathrm{m}, \mathrm{d}_{90}$ is $136.2 \mu \mathrm{m}$, and the average particle size $\mathrm{d}_{\mathrm{m}}$ is $38.08 \mu \mathrm{m}$. The active components of fly ash are mainly $\mathrm{SiO}_{2}, \mathrm{~A}_{2} \mathrm{O}_{3}$ and $\mathrm{CaO}$. Because the content of $\mathrm{CaO}$ in fly ash is generally low, the main active components are $\mathrm{SiO}_{2}$ and $\mathrm{Al}_{2} \mathrm{O}_{3}$ (as shown in Table 2).

Table 2. Fly ash composition.

\begin{tabular}{lcccccc}
\hline Composition & $\mathrm{SiO}_{2}$ & $\mathrm{AI}_{2} \mathbf{O}_{3}$ & $\mathrm{Fe}_{2} \mathbf{O}_{3}$ & $\mathbf{C a O}$ & $\mathbf{K}_{2} \mathbf{O}$ & Others \\
\hline Content (\%) & 35.6 & 11.9 & 25.5 & 16.4 & 4.0 & 6.6 \\
\hline
\end{tabular}

Cement: P.O42.5 type cement was used. The $28 \mathrm{~d}$ compressive strength is $48.0 \mathrm{MPa}$. Its composition is shown in Table 3.

Table 3. Cement composition.

\begin{tabular}{lcccccc}
\hline Composition & $\mathrm{CaO}$ & $\mathrm{SiO}_{2}$ & $\mathrm{AL}_{2} \mathrm{O}_{3}$ & $\mathrm{MgO}$ & $\mathrm{Fe}_{2} \mathrm{O}_{3}$ & Others \\
\hline Content $(\%)$ & 65.08 & 22.36 & 5.53 & 1.27 & 3.46 & 2.30 \\
\hline
\end{tabular}

\subsection{Experimental Schemes}

Fix paste mass fraction of $78 \%$, keep the quality of water and cement unchanged, increase the amount of fly ash from $0 \%$ to $30 \%$ [22] and study its effect on the rheological properties and compressive strength of the paste material. The specific proportions are shown in Table 4.

Table 4. Proportion of aeolian sand-fly ash-based filling paste.

\begin{tabular}{cccccc}
\hline \multirow{2}{*}{ Group } & \multicolumn{3}{c}{ Mass Ratio of Coal Mine Filling Paste } & \multirow{2}{*}{ Fly Ash Content (\%) } \\
\cline { 2 - 5 } & Aeolian Sand (g) & Fly Ash (g) & Cement (g) & Water (g) & \\
\hline I & 281 & 0 & 70 & 99 & 0 \\
II & 255 & 26 & 70 & 99 & 9.5 \\
III & 228 & 53 & 70 & 99 & 22.5 \\
IV & 202 & 79 & 70 & 99 & 30 \\
V & 176 & 105 & 70 & & \\
\hline
\end{tabular}

Experimental process: In this experiment, we tested the rheological properties and mechanical properties of the paste material. The rheology experiment was performed with a HAAKE rheometer (Figure 3a) and a $500 \mathrm{~mL}$ beaker. The speed of the rheometer can be controlled within the range of $0.001-157 \mathrm{rad} / \mathrm{s}$, and the torque resolution is $0.01 \mathrm{mNm}$. In the experiment, the control variable method was used to obtain the backfill body rheology curve by controlling the shear rate (increased from $0.1 \mathrm{~s}^{-1}$ to $100 \mathrm{~s}^{-1}$ in $180 \mathrm{~s}$ ) and analyzing its rheological properties by means of linear fitting evaluation. The mechanical properties test of the filling body uses a cylindrical steel mold of $50 \mathrm{~mm} \times 100 \mathrm{~mm}$. After the specimens were cured for 1 day, they could be formed and demolded. After the mold was removed, the specimens were numbered and were next placed in the curing box (Figure $3 \mathrm{c}$ ).

After the curing time ( $3 \mathrm{~d}, 7 \mathrm{~d}, 14 \mathrm{~d}, 28 \mathrm{~d}, 90 \mathrm{~d})$ [28], the MTS electronic universal testing machine (Figure 3b) was used to test the uniaxial compressive strength (UCS) of the test piece. The test machine can achieve force control in the range of $1 \mathrm{~N}$ to $50 \mathrm{kN}$ and can accurately obtain the filling compressive strength value of the body. A cube sample with a side length of $5 \mathrm{~mm}$ was cut from the center of the sample. Remove the dust on the surface of the sample with a rubber suction cup to obtain a fresh and clean section, and then apply a layer of metal conductive film in the vacuum coating machine to the sample used for scanning electron microscope (SEM) observation [30]. The specific experimental process is shown in Figure 4. 


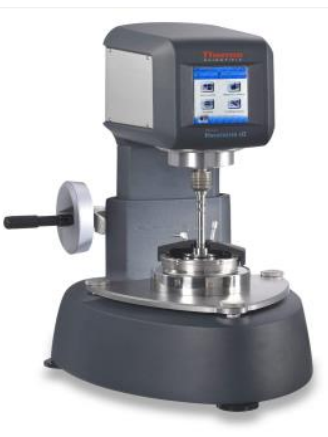

(a) Rheometer

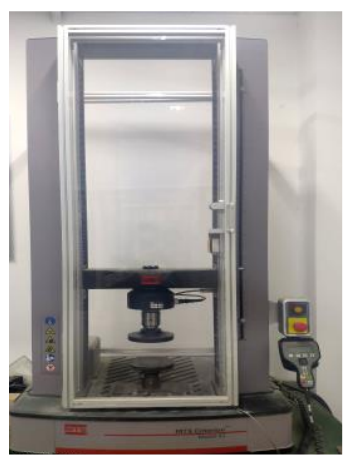

(b) UCS test machine

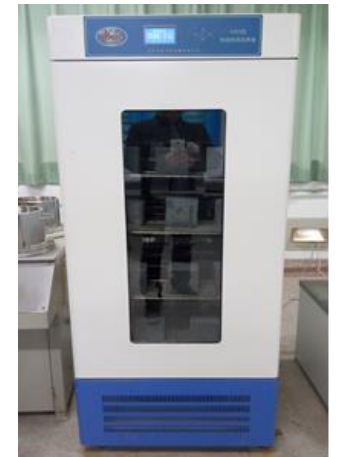

(c) Standard conservation box

Figure 3. Experimental equipment.

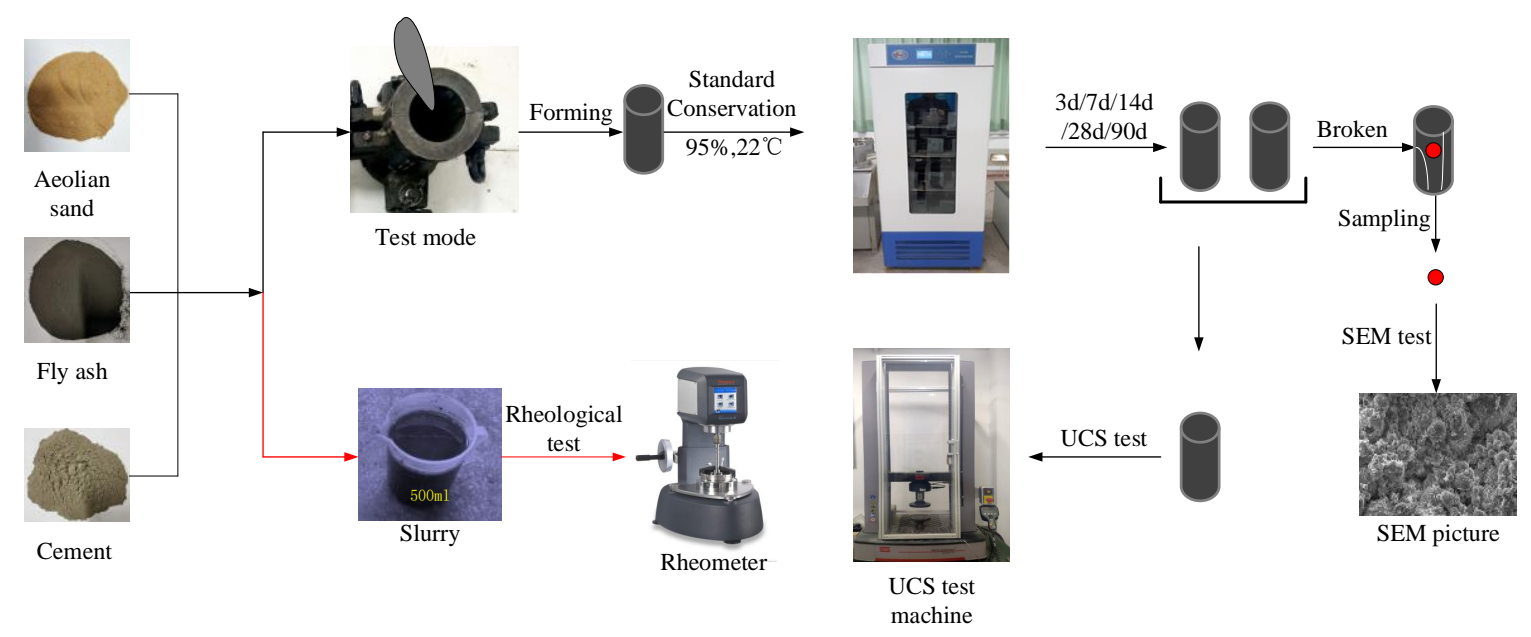

Figure 4. Experimental flowchart.

\section{Results and Discussion}

During the experiment, two rheological experiments were carried out on the same ratio of aeolian sand-fly ash-based filling slurry. The uniaxial strength test was carried out on two cylindrical specimens with the same ratio, and the average value of the two tests was taken as the experimental data; the experimental results are shown in Table 5.

Table 5. Experimental data.

\begin{tabular}{cccccccc}
\hline \multirow{2}{*}{ Group } & \multirow{2}{*}{ Yield Stress/Pa } & \multirow{2}{*}{ Plastic Viscosity/(Pa·s) } & \multicolumn{5}{c}{ Compressive Strength/MPa } \\
\cline { 4 - 7 } & & & $\mathbf{3 ~ d}$ & $\mathbf{7 ~ d}$ & $\mathbf{1 4} \mathbf{~ d}$ & $\mathbf{2 8 ~ d}$ & $\mathbf{9 0 ~ d}$ \\
\hline I & 14.71 & 1.107 & 0.309 & 2.725 & 4.653 & 4.482 & 5.989 \\
II & 22.54 & 1.417 & 0.74 & 3.345 & 5.289 & 5.417 & 8.699 \\
III & 30.11 & 1.689 & 1.68 & 3.161 & 5.486 & 5.995 & 8.806 \\
IV & 52.05 & 3.052 & 1.953 & 3.239 & 5.096 & 6.302 & 11.399 \\
V & 97.26 & 4.792 & 2.358 & 4.053 & 6.134 & 9.444 & 15.033 \\
\hline
\end{tabular}

Notes: 1 . When the content of fly ash is higher than $30 \%$, the filling slurry becomes very thick and the fluidity of the paste cannot meet the working requirements; 2 . The compressive strength value of the test piece is the average of two test pieces with the same proportion. 


\subsection{Rheological Test Results}

\subsubsection{Rheological Model, Yield Stress and Plastic Viscosity}

In order to determine the rheological model of aeolian sand-fly ash-based filling slurry, we fitted the rheological curve of filling slurry with different fly ash content, and analyzed the rheological curve of filling slurry with $15 \%$ fly ash content, as shown in Figure 5.

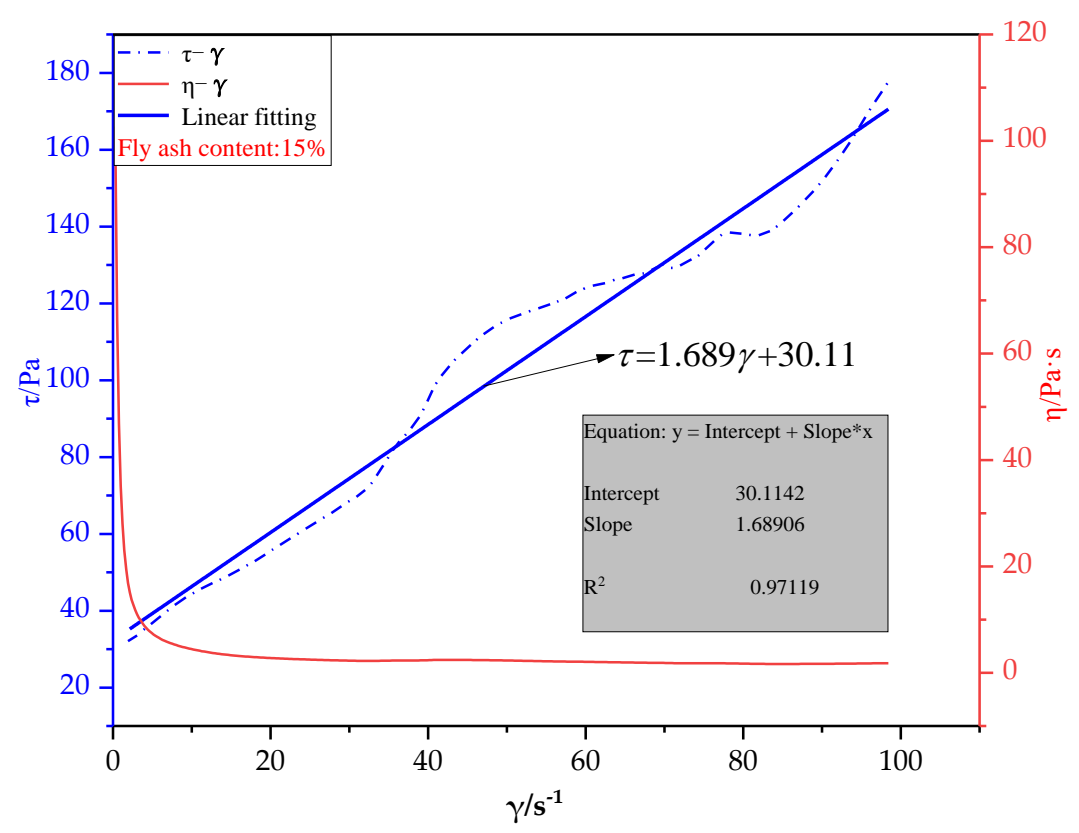

Figure 5. The relation curve between shear stress and shear rate and the relation curve between viscosity and shear rate.

In the process of increasing the shear rate from $0 \mathrm{~s}^{-1}$ to $100 \mathrm{~s}^{-1}$, it can be found that the shear rate meets a linear relationship with the shear stress. The shear stress increases with the increase of the shear rate. It is found that the shear rate and shear stress satisfy a linear function relationship, and the relationship is $\tau=1.689 \gamma+30.11$, where $\tau$ represents the shear stress, $\gamma$ represents the shear rate, and where the coefficient of determination is 0.97119 . It is not difficult to see that the rheological characteristics of aeolian sand-fly ash-based filling slurry conforms to the law of the Bingham model [31,32]: $\tau=\eta \gamma+\tau_{0}$, where $\eta$ is the plastic viscosity and $\tau_{0}$ is the yield stress. Therefore, when the fly ash content is $15 \%$, the plastic viscosity of the filling slurry is $1.689 \mathrm{~Pa} \cdot \mathrm{s}$ and the yield stress is $30.11 \mathrm{~Pa}$. See Table 5 for the yield stress and plastic viscosity of backfill slurry, when the fly ash content is $0 \%, 7.5 \%, 22.5 \%$, and $30 \%$.

The deformation and flow characteristics of the filling slurry under the external force are the key factors that guide the selection of the field filling pipeline system. Figure 5 shows the relationship between the amount of fly ash and the shear yield stress and plastic viscosity of the backfill body slurry when the shear rate is increased from $0.1 \mathrm{~s}^{-1}$ to $100 \mathrm{~s}^{-1}$ at a constant rate within $180 \mathrm{~s}$.

As shown in Figure 6a, when the amount of fly ash is increased from $0 \%$ to $30 \%$, the shear yield stress of the slurry increases from the original 14.71 Pa to 97.26 Pa. By fitting the data, we found that the fly ash content and the shear yield force satisfy a quadratic function relationship within a certain error range, and the relationship is $y=17.14-0.8 x+0.11 x^{2}$. The shear yield stress of the paste slurry is proportional to the square of the fly ash content. As the fly ash content increases, the ability of the filling slurry to resist deformation also increases, and its plasticity increases. Conversely, the lower the fly ash content, the weaker the paste slurry's ability to resist deformation. 


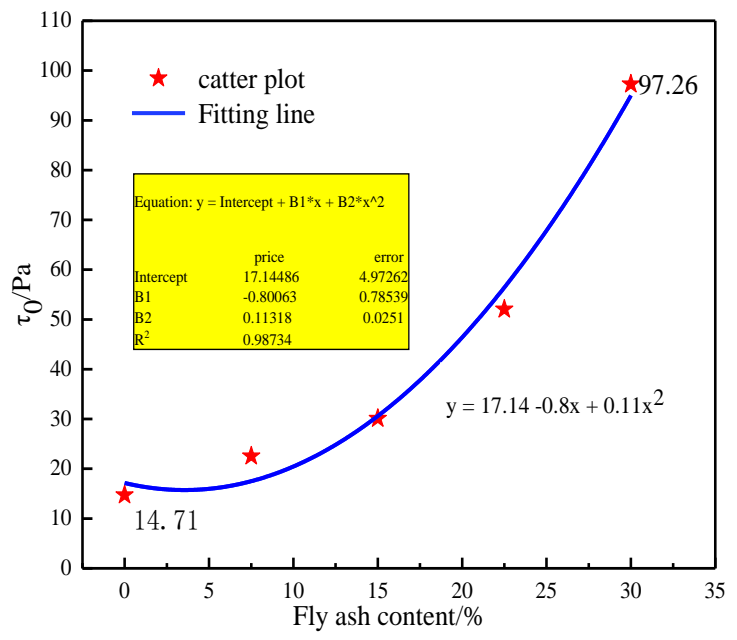

(a) Yield stress

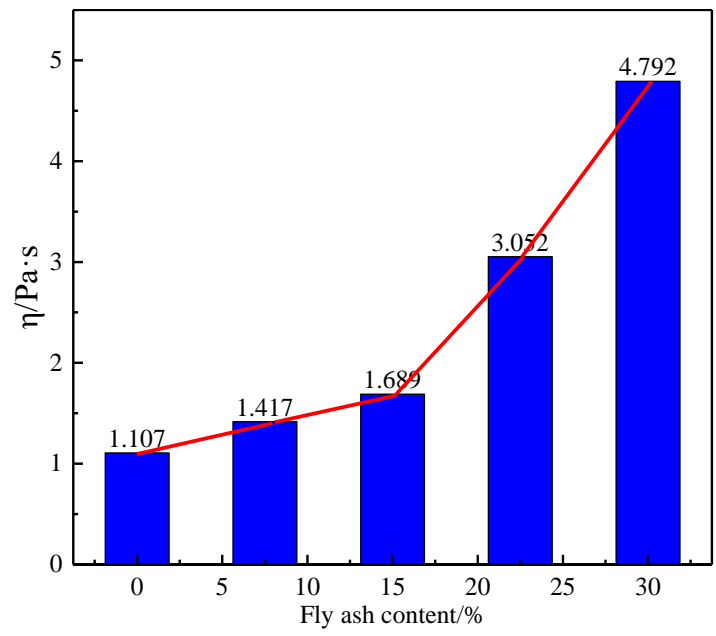

(b) Plastic viscosity

Figure 6. Effect of fly ash content on shear yield stress and plastic viscosity of slurry.

Plastic viscosity is the main factor affecting the fluidity of the filling slurry. As shown in Figure 6b, as the amount of fly ash increases, the plastic viscosity also increases. When the fly ash content is $30 \%$, the plasticity viscosity can reach the maximum value of $4.79 \mathrm{~Pa} \cdot \mathrm{s}$ in this experiment. Increasing the amount of fly ash can improve the cohesiveness of the slurry, which is conducive to the formation of a "plunger flow" that does not segregate, settle, nor bleed [33]. However, the fluidity of the slurry is also weakened, which is not conducive to pumping the slurry.

This is mainly because in the aeolian sand-fly ash-based filling slurry, with the increase of fly ash content, the proportion of fine particles increases, and the friction between particles also increases. Moreover, with the increase of fly ash particles, aeolian sand particles are gradually replaced by finer fly ash particles. The fly ash particles are evenly distributed in the basic phase of the filling slurry; because of its fine particles and large specific surface area, the particle surface easily absorbs more water [34], which plays the role of "water reducing agent", making the slurry thicker, and helps to improve the uniformity of the fresh and hardened paste [35]. At the same time, the fine fly ash particles filled in the capillary pores of the slurry, reduce the porosity and makes the structure compact.

\subsubsection{Thixotropic Properties}

Thixotropy refers to the phenomenon that the consistence of the filling slurry decreases (increases) when sheared, and increases (decreases) when the shearing stops [36]. The thixotropic characteristics of the aeolian sand-fly ash-based backfill body slurry were analyzed by the thixotropic ring method. The area of the thixotropic ring reflected the thixotropy of the slurry. Figure 7a shows, the up and down flow curves of different fly ash-filled backfill body slurry measured in a 3 minute experiment. In the entire range of shear rate $\left(0.1 \mathrm{~s}^{-1}-100.1 \mathrm{~s}^{-1}\right)$, when the fly ash content exceeds $15 \%$, the upward flow curve of the filling slurry is on the higher side of the downward flow curve. As shown in Figure $7 \mathrm{~b}$, the area of the thixotropic ring increases with the increase in the amount of fly ash.

In the process of increasing the amount of fly ash from $0 \%$ to $30 \%$, the area increases from 212.46 $\mathrm{Pa} / \mathrm{s}$ to $6482 \mathrm{~Pa} / \mathrm{s}$. When the amount of fly ash is $22.5 \%-30 \%$, the area of thixotropic ring increases very obviously, the consistency of the slurry reaches the maximum value of this test, the upper and lower shear stresses show obvious differences, and the rising curve shows obvious stress overshoot. There are obvious fluctuations and bending phenomena in the rising stress curve, and then gradually decrease in steady state; this is due to the greater friction between the ultra-multiple fly ash particles, and the fine fly ash particles will fill the slurry. Among the capillary pores, the slurry has dense pores and can only be destroyed by large shear forces [37,38]. Therefore, in the aeolian sand-fly ash-based filling material, 
the amount of fly ash is positively related to the consistency of the filling slurry. The larger the amount of fly ash, the thicker the slurry and the greater the thixotropy. But as thixotropic properties increase, the fluidity of the slurry also decreases.

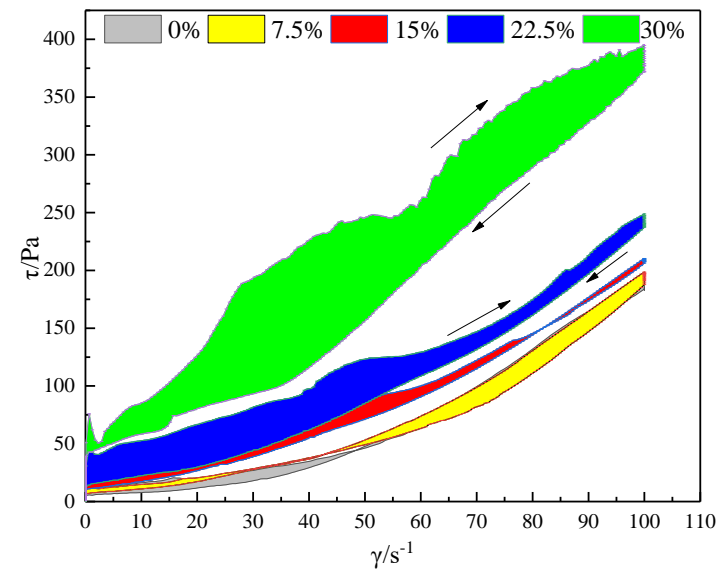

(a) Thixotropic ring

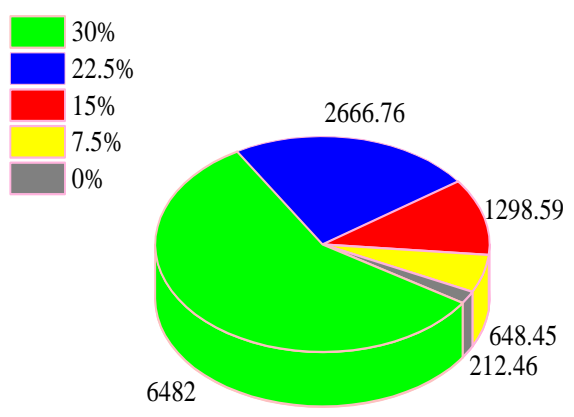

(b) Thixotropic ring area

Figure 7. Thixotropic characteristics.

\subsubsection{Rheological Properties at Constant Shear Rate}

In the Bingham model, when the shear rate is constant, the shear force and viscosity meet a proportional relationship. For the convenience of research, we controlled the shear rate to $50 \mathrm{~s}^{-1}$, as shown in Figure $8 \mathrm{a}, \mathrm{b}$. The higher the content of fly ash is, the higher the viscosity curve and the higher the shear stress curve. When the fly ash content is less than $7.5 \%$, the stress curve and viscosity curve change smoothly during the entire shearing process. When the content of fly ash reaches $30 \%$, there is a significant difference between the stress curve and viscosity curve after shear stabilization and its initial height, which shows the ability of resisting deformation of slurry, is improved by fly ash in the slurry. That is to say, the yield stress of the slurry is increased. At the beginning of the shear experiment, the rotor needs to overcome a large yield stress to reach a stable state. When the content of fly ash is low, the yield stress is small, so the curve changes gently.

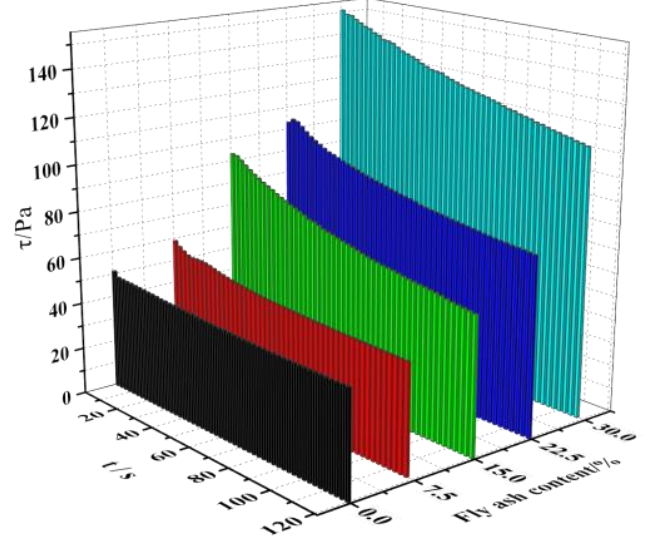

(a) Shear stress

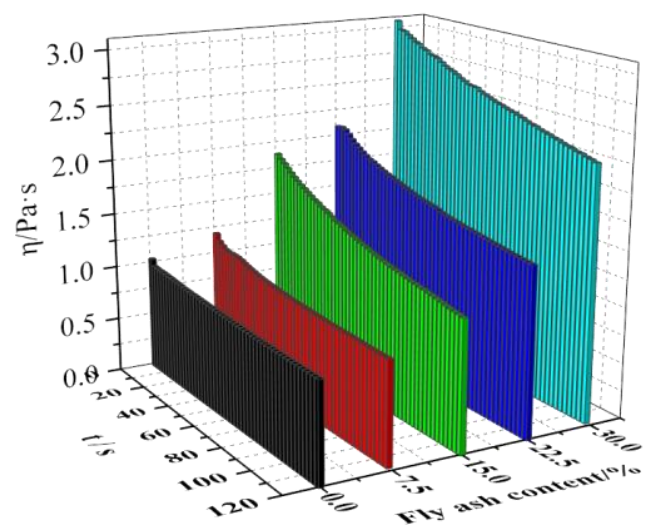

(b) Plastic viscosity

Figure 8. Rheological curve at constant shear rate.

\subsection{Mechanical Test Results}

The determination of the compressive performance of the filling paste is the key to the filling and mining of coal mines, which will directly affect the filling effect. Reasonable strength requirements are 
the guarantee of safe mining. For fly ash filling material, the strength development of the filling body under different curing time and fly ash content is of great significance to filling mining.

As shown in Figure 9, as the amount of fly ash increases, the strength of the backfill body generally increases. The compressive strength of the test specimen No.I ( $0 \%$ fly ash content) on the curing time of 90 days is only about $6.0 \mathrm{MPa}$. The compressive strength of No.V (30\% fly ash content) can reach 15.0 MPa, which is doubled compared to the compressive strength of No.I ratio. It can be seen that the amount of fly ash has played a key role in improving the later strength of the paste. At 7 days and 14 days of curing time, the strength of the test specimens is concentrated at about 3.24 MPa and 5.1 MPa respectively. At the time of 3 days of curing, the strength of filling the body of No.V can reach about eight times of that of No.I ratio. In summary, the impact of fly ash on the filling body is mainly reflected in the enhancement of the strength at the later stage, and the impact on the strength of the filling body in the middle period is not obvious. This is mainly because during the development of the strength of the filling body, it first experienced the hydration reaction of the cement, and the $\mathrm{C}-\mathrm{H}$ generated from the hydration of the cement corroded the surface of the fly ash, which in turn stimulated the volcanic ash reaction of the fly ash [39]. Volcanic ash reaction of fly ash is lagging behind the hydration reaction of cement. The secondary product of the delayed reaction is filled in the pores of cement hydrates, which can greatly reduce the porosity of the backfill body and increase the later strength of the backfill body [40].

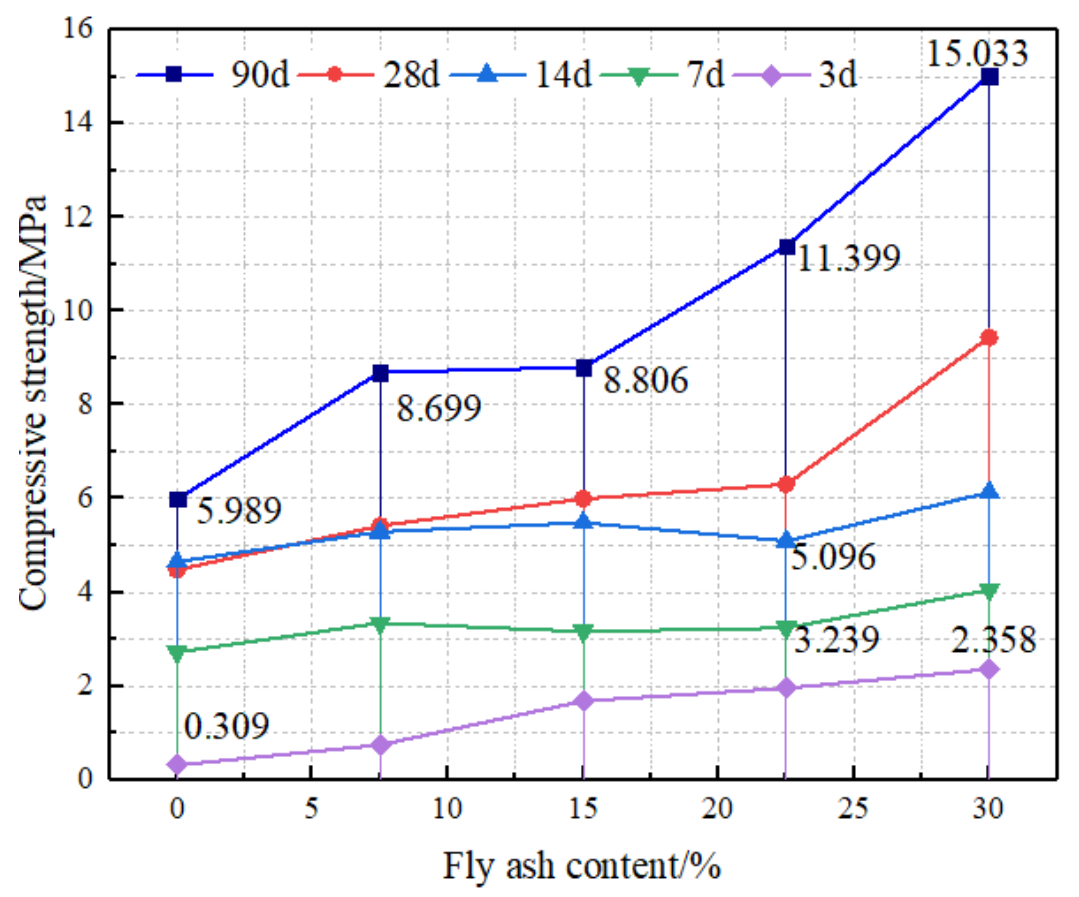

Figure 9. Effect of fly ash content on strength of backfill.

As shown in Figure 10, materials such as $\mathrm{C}_{2} \mathrm{~S}, \mathrm{G}_{3} \mathrm{~S}, \mathrm{C}_{3} \mathrm{~A}$, and $\mathrm{C}_{4} \mathrm{AF}$ in cement particles react with water to undergo a series of hydration reactions. The hydration products are: calcium hydroxide (C-H), water calcium aluminate (C-A-H), calcium ferric aluminate (C-S-F-H), etc. [34]. Among these hydration products, $\mathrm{C}-\mathrm{H}$ is an active activator of fly ash in the cement environment, and it is in the form of flake crystals. Compared with other hydration products of cement, its composition is the purest. $\mathrm{C}-\mathrm{H}$ develops crystals on the surface of fly ash to form an alkaline thin film solution. The active $\mathrm{SiO}_{2}$ and $\mathrm{Al}_{2} \mathrm{O}_{3}$ in fly ash react with the flake $\mathrm{C}-\mathrm{H}$ crystals formed by hydration of cement to form $\mathrm{C}-\mathrm{S}-\mathrm{H}$ and $\mathrm{C}-\mathrm{A}-\mathrm{H}$ gel. Although the reaction is slow, it has a great influence on the later strength $[23,41]$.

Fly ash itself has only potential activity. In the absence of admixtures, fly ash generally does not produce self-setting. However, the reaction of active $\mathrm{SiO}_{2}, \mathrm{Al}_{2} \mathrm{O}_{3}$ in fly ash and $\mathrm{Ca}(\mathrm{OH})_{2}$ released 
from the hydration of cement clinker minerals can make its gelling properties appear, and finally the strength of the filling body is gradually increased.
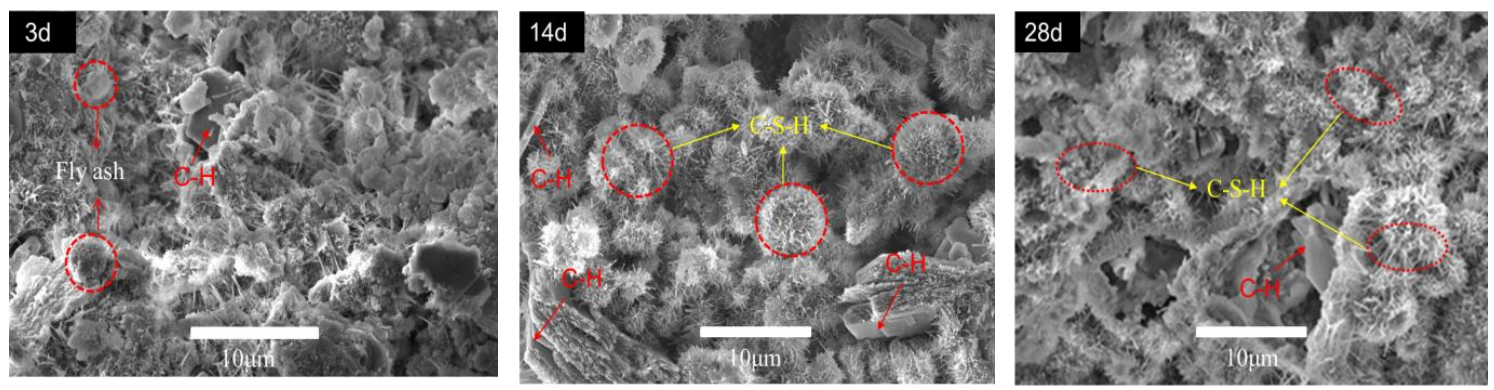

Figure 10. SEM pictures of filling body with ratio of No. III in different curing age.

\section{Discussion}

In this paper, the rheological properties of the aeolian sand-fly ash-based filling slurry with $0-30 \%$ fly ash of aeolian sand fly ash based filler are studied, and the strength development rule of the filler under different fly ash content and curing age (3-90 d) is analyzed. It is found that the fly ash content is positively related to viscosity and yield stress, and the strength increases with the increase of fly ash content and age. When the content of fly ash is less than $15 \%$, although the fluidity of filling slurry is excellent, the bearing strength cannot meet the requirements (more than 6.0 MPa). When the content of fly ash is more than $15 \%$, the support strength can be satisfied after 28 days of curing. However, with the increase of the content of fly ash, the fluidity of filling slurry will be weakened. When the content of fly ash is $30 \%$, the plastic viscosity of the slurry reaches $4.792 \mathrm{~Pa} \cdot \mathrm{s}$ and the consistency of the slurry is relatively large, which is not conducive to pumping, which is consistent with the research results of many scholars [42-44]. When fly ash content is $15 \%$ and $22.5 \%$, both the fluidity and bearing strength are considered as the ideal material ratio for filling and mining in Shanghe coal mine after field verification [1]. Unfortunately, our experiment did not design longer curing time (such as $180 \mathrm{~d}$ ) [45]. Some scholars studied found that with the increase of fly ash content, the workability and mechanical strength of cement paste backfill (CPB) increase, and when they reach the maximum, they decrease with the increase of fly ash content [24,46]. However, in this experiment, we did not find the strength inflection point of the filling specimen; further research is needed. In a future study, we will study the strength development law of aeolian sand-fly ash-based filling slurry with higher content of fly ash and at a longer curing period $(180 \mathrm{~d})$, and the rheological characteristics of filling slurry under time-varying characteristics. This promotes the treatment of solid waste and the efficient development of coal resources; it has a great significance to the development of the green mining industry. It not only provided a basis for the selection of filling ratio and pipeline transportation parameters in the safe filling mining of the Yushenfu mining area in Northern Shaanxi, but it also has certain reference significance for filling mining under the conditions of similar mines in the world.

\section{Conclusions}

In this paper, the rheological properties of the aeolian sand-fly ash-based filling slurry with different fly ash content are studied by experiments, and the strength development law of the filling body under different age and fly ash content is studied from the macroscopic and microscopic points of view. The main conclusions of this study are as follows:

(1) The rheological properties of aeolian sand-fly ash-based filling slurry conform to the Bingham model.

(2) Thixotropy of aeolian sand-fly ash-based filling slurry increases with the increase of fly ash content. When the amount of fly ash is $22.5 \%-30 \%$, the area of the thixotropic ring increases very significantly. 
(3) The fly ash content and the shear yield force meet a quadratic function relationship of $y=17.14$ $-0.8 x+0.11 x^{2}$. As the fly ash content increases, the backfill body's resistance to deformation increases and its plasticity increases.

(4) Increasing the amount of fly ash can improve the cohesiveness of the slurry, which is beneficial to the slurry and the slurry does not segregate. When the fly ash content is $30 \%$, the plastic viscosity can reach the maximum value of $4.79 \mathrm{~Pa} \cdot \mathrm{s}$ in this experiment. However, with the increase of the amount of fly ash, the fluidity of the slurry also weakens, which is not conducive to pumping the slurry.

(5) The strength of aeolian sand based fly ash filling increases with the increase of fly ash content; the influence of fly ash on the strength of the filling body is mainly reflected in the enhancement of the strength at the later stage, but the influence on the medium-term strength is not obvious.

Author Contributions: Conceptualization, L.W.; data curation, X.L. and W.S.; formal analysis, L.W.; funding acquisition, L.L.; investigation, Z.F. and Y.T. and J.S.; methodology, Z.F.; resources, B.Z.; software, X.L.; supervision, X.S.; validation, X.S.; writing-original draft, X.S.; writing-review and editing, Z.F. All authors have read and agreed to the published version of the manuscript.

Funding: This research was funded by the National Natural Science Foundation of China (No. 51874230, 51674188, 51874229, 51504182), the Innovation Support Program (Science and Technology Innovation Team) Project Funding of Shaanxi Province of China (No. 2018TD-038), and the Shaanxi Innovative Talents Cultivate Program-New-star Plan of Science and Technology (No. 2018KJXX-083).

Conflicts of Interest: The authors declare no conflict of interest concerning the publication of this paper.

\section{References}

1. Shao, X.P.; Li, X.; Wang, L.; Fang, Z.Y.; Zhao, B.; Liu, E.; Tao, Y.; Liu, L. Study on the pressure-bearing law of backfilling material based on three-stage strip backfilling mining. Energies 2020, 13, 211. [CrossRef]

2. Zingano, A.; Weiss, A. Subsidence over room and pillar retreat mining in a low coal seam. Int. J. Min. Sci. Technol. 2019, 29, 51-57. [CrossRef]

3. Yu, Y.; Deng, K.Z.; Fan, H.D. Long-term stability evaluation and coal pillar design methods for strip mining. J. China Coal Soc. 2017, 42, 3089-3095.

4. Qian, M.G.; Xu, J.L.; Miao, X.X. Green technique in coal mining. J. China Univ. Min. Technol. 2003, 32, 343-348.

5. Ma, L.Q.; Zhang, D.S.; Jin, Z.Y.; Wang, S.T.; Yu, Y.H. Theories and methods of efficiency water conservation mining in short-distance coal seams. J. China Coal Soc. 2019, 44, 727-738.

6. Chen, S.J.; Du, Z.W.; Zhang, Z.; Zhang, H.W.; Xia, Z.G.; Feng, F. Effects of chloride on the early mechanical properties and microstructure of gangue-cemented paste backfill. Constr. Build. Mater. 2020, 235, 117504. [CrossRef]

7. Liu, L.; Xin, J.; Huan, C.; Qi, C.C.; Zhou, W.W.; Song, K.I. Pore and strength characteristics of cemented paste backfill using sulphide tailings: Effect of sulphur content. Constr. Build. Mater. 2020, 237, 117452. [CrossRef]

8. Yin, B.; Kang, T.H.; Kang, J.T.; Chen, Y. Experimental and Mechanistic Research on Enhancing the Strength and Deformation Characteristics of Fly-Ash-Cemented Filling Materials Modified by Electrochemical Treatment. Energy Fuels 2018, 32, 3614-3626. [CrossRef]

9. Sun, Q.; Zhang, J.; Zhou, N. Study and discussion of short- strip coal pillar recovery with cemented paste backfill. Int. J. Rock Mech. Min. Sci. 2018, 104, 147-155. [CrossRef]

10. Wang, P.; Hu, Y.N.; Cheng, H.F. Municipal solid waste (MSW) incineration fly ash as an important source of heavy metal pollution in China. Environ. Pollut. 2019, 252, 461-475. [CrossRef]

11. Baram, M.S.; Sharma, J.; Singh, R.; Pugazhendhi, A. Industrial wastes: Fly ash, steel slag and phosphogypsumpotential candidates to mitigate greenhouse gas emissions from paddy fields. Chemosphere 2020, 241, 124824.

12. Bhatt, A.; Priyadarshini, S.; Mohanakrishnan, A.A.; Abri, A.; Sattler, M.; Techapaphawit, S. Physical, chemical, and geotechnical properties of coal fly ash: A global review. Case Stud. Constr. Mater. 2019, 11, e00263. [CrossRef]

13. Shekhovtsova, J.; Kovtun, M.; Kearsley, E.P. Evaluation of short- and long-term propertiesof heat-cured alkali-activated fly ash concrete. Mag. Concr. Res. 2015, 67, 897-905. [CrossRef] 
14. Liu, X.; Nair, S.; Aughenbaugh, K.; van Oort, E. Mud-to-cement conversion of non-aqueousdrilling fluids using alkali-activated fly ash. J. Pet. Sci. Eng. 2019, 182, 106242. [CrossRef]

15. Fládr, J.; Bílý, P.; Chylík, R.; Prošek-Solid State Phenomena, Z. Macroscopic and Microscopic Properties of High Performance Concrete with Partial Replacement of Cement by Fly Ash. Solid State Phenom. 2019, 292, 108-113. [CrossRef]

16. Teixeira, E.R.; Camões, A.; Branco, F.G.; Aguiar, J.B.; Fangueiro, R. Recycling of biomassand coal fly ash as cement replacement material and its effect on hydration and carbonation of concrete. Waste Manag. 2019, 94, 39-48. [CrossRef]

17. Krishnaraj, L.; Ravichandran, P.T. Investigation on grinding impact of fly ash particles and its characterization analysis in cement mortar composites. Ain Shams Eng. J. 2019, 10, 267-274. [CrossRef]

18. Dong, H.Z.; Feng, G.; Guo, Y. Pipe transportation characteristics of filling slurry in Xinyang mine. J. Min. Saf. Eng. 2013, 30, 880-885.

19. Fu, Z.G.; Qiao, D.P.; Guo, Z.L.; Jincheng, X.; Fei, H.; Jiaxin, W. Experimental research on mixture proportion and strength of cemented hydraulic fill with waste rock and eolian sand based on RSM-BBD. J. China Coal Soc. 2018, 43, 694-703.

20. Fang, K.; Fall, M. Chemically Induced Changes in the Shear Behaviour of Interface Between Rock and Tailings Backfill Undergoing Cementation. Rock Mech. Rock Eng. 2019, 52, 3047-3062. [CrossRef]

21. Jiang, D.B.; Li, X.G.; Lv, Y.; Zhou, M.K.; He, C.H.; Jiang, W.; Liu, Z.; Li, C. Utilization of limestone powder and fly ash in blended cement: Rheology, strength and hydration characteristics. Constr. Build. Mater. 2020, 232, 117228. [CrossRef]

22. Yin, B.; Kang, T.H.; Kang, J.T.; Chen, Y.; Wu, L.; Du, M. The research of the hydration kinetics process and hydration mechanismof fly ash paste filling materials. Chin. J. Rock Mech. Eng. 2018, 37, 4384-4394.

23. Ren, A.; Feng, G.R.; Guo, Y.X.; Qi, T.Y.; Guo, J.; Zhang, M. Influence on performance of coal mine filling paste with fly ash. J. China Coal Soc. 2014, 39, 2374-2380.

24. Deng, X.J.; Zhang, J.X.; Klein, B.; Zhou, N. Benjamin deWit, Experimental characterization of the influence of solid components on the rheological and mechanical properties of cemented paste backfill. Int. J. Miner. Process. 2017, 168, 116-125. [CrossRef]

25. Jiao, D.W.; Shi, C.J.; Yuan, Q. Influences of shear-mixing rate and fly ash on rheological behavior of cement pastes under continuous mixing. Constr. Build. Mater. 2018, 188, 170-177. [CrossRef]

26. Ren, Q.; Jiang, Z.W.; Li, H.X.; Zhu, X.P.; Chen, Q. Fresh and hardened properties of self-compacting concrete using silicon carbide waste as a viscosity-modifying agent. Constr. Build. Mater. 2019, 200, 324-332. [CrossRef]

27. Dong, W.; Lyu, S.; Xue, G. Effect of Aeolian Sand and Fly Ash Content on Mechanical Properties of Concrete. Bull. Chin. Ceram. Soc. 2018, 37, 2320-2325.

28. Cao, X.F.; Tang, Y.C.; Deng, N.D.; Shang, H.; Wang, Y. Aeolian Sand Paste Filling Material Ratio Based on Repeated Orthogonal Test. Saf. Coal Mines 2019. [CrossRef]

29. Agrawal, U.S.; Wanjari, S.P.; Naresh, D.N. Impact of replacement of natural river sand with geopolymer fly ash sand on hardened properties of concrete. Constr. Build. Mater. 2019, 209, 499-507. [CrossRef]

30. Liu, L.; Fang, Z.Y.; Qi, C.C. Experimental investigation on the relationship between pore characteristics and unconfined compressive strength of cemented paste backfill. Constr. Build. Mater. 2018, 179, $254-264$. [CrossRef]

31. Wang, J.; Wu, H.J.; Feng, X.W.; Pi, A.G.; Li, J.Z.; Huang, F.L. Dynamic spherical cavity expansion analysis of concrete using the Bingham liquid constitutive model. Int. J. Impact Eng. 2018, 120, 110-117. [CrossRef]

32. Liu, Y.; Shi, C.J.; Jiao, D.W.; An, X.P. Rheological Properties, Models and Measurements for Fresh Cementitious Materials-A Short Review. J. Chin. Ceram. Soc. 2017, 45, 708-716.

33. Zhou, H.Q.; Hou, C.J.; Sun, X.K.; Qu, Q.D.; Chen, D.J. Solid waste paste filling for none-village-relocation coal mining. J. China Univ. Min. Technol. 2004, 33, 154-158.

34. Sun, Q.; Tian, S.; Sun, Q.W.; Li, B.; Cai, C.; Xia, Y.; Wei, X.; Mu, Q. Preparation and microstructure of fly ash geopolymer paste backfill material. J. Clean. Prod. 2019, 225, 376-390. [CrossRef]

35. Agnieszka, W.; Lidia, B.; Wojciech, F. Fly ash as low cost and environmentally friendly backfill body and its effect on the properties of mix asphalt. J. Clean. Prod. 2019, 235, 493-502. 
36. Javid, A.A.S.; Ghoddousi, P.; Amiri, G.G.; Donyadideh, K. A new photogrammetry method to study the relationship between thixotropy and bond strength of multi-layers casting of self-consolidating concrete. Constr. Build. Mater. 2019, 204, 530-540. [CrossRef]

37. Jiao, D.W.; Shi, C.J.; Yuan, Q. Time-dependent rheological behavior of cementitious paste under continuous shear mixing. Constr. Build. Mater. 2019, 226, 591-600. [CrossRef]

38. Park, C.K.; Noh, M.H.; Park, T.H. Rheological properties of cementitious materials containing mineral admixtures. Cem. Concr. Res. 2005, 35, 842-849. [CrossRef]

39. Marsh, B.K.; Day, R.L. Pozzolanic and cementitious reactions of fly ash in blended cement pastes. Cem. Concr. Res. 1988, 18, 301-310. [CrossRef]

40. Chindasiriphan, P.; Yokota, H.; Pimpakan, P. Effect of fly ash and superabsorbent polymer on concrete self-healing ability. Constr. Build. Mater. 2020, 233, 116975. [CrossRef]

41. Deschner, F.; Winnefeld, F.; Lothenbach, B.; Seufert, S.; Schwesig, P.; Dittrich, S.; Goetz-Neunhoeffer, F.; Neubaue, J. Hydration of Portland cement with high replacement by siliceous fly ash. Cem. Concr. Res. 2012, 42, 1389-1400. [CrossRef]

42. Liu, L.; Fang, Z.Y.; Qi, C.C.; Zhang, B.; Guo, L.; Song, K.I.I.L. Numerical study on the pipe flow characteristics of the cemented paste backfill slurry considering hydration effects. Powder Technol. 2019, 343, 454-464. [CrossRef]

43. Horiuchi, S.; Odawara, T.; Takiwaki, H. Coal fly ash slurries for back-filling. Stud. Environ. Sci. 1991, 48, 545-552.

44. Shaban, W.M.; Yang, J.; Su, H.; Liu, Q.-F.; Tsang, D.C.W.; Wang, L.; Xie, J.; Li, L. Properties of recycled concrete aggregates strengthened by different types of pozzolan slurry. Constr. Build. Mater. 2019, 216, 632-647. [CrossRef]

45. Min, C.D.; Li, X.B.; He, S.Y.; Zhou, S.T.; Zhou, Y.N. Effect of mixing time on the properties of phosphogypsum-based cemented backfill. Constr. Build. Mater. 2019, 210, 564-573. [CrossRef]

46. Yin, B. Research on the Fly Ash Cemented Filling Materials and Its Modification and Further Application. Ph.D. Thesis, Taiyuan University of Technology, Taiyuan, China, 2018.

(C) 2020 by the authors. Licensee MDPI, Basel, Switzerland. This article is an open access article distributed under the terms and conditions of the Creative Commons Attribution (CC BY) license (http://creativecommons.org/licenses/by/4.0/). 